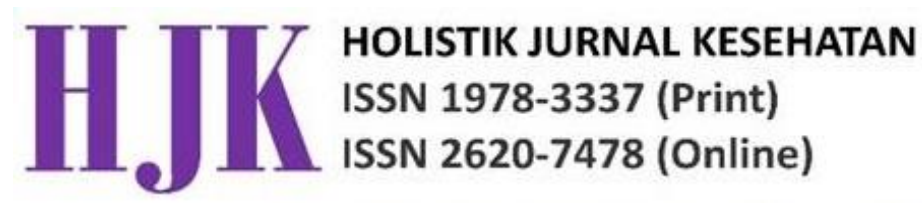

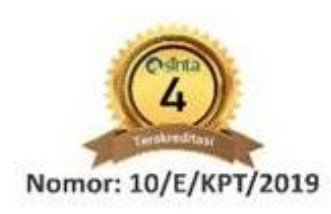

INFORMASI ARTIKEL

Received: August, o2, 2021

Revised: August, 23, 2021

Available online: September, 06, 2021

at : http://ejurnalmalahayati.ac.id/index.php/holistik

\section{Validitas instrumen European Quality of Life (EQ-5D-5L) versi Indonesia untuk menilai kualitas hidup penderita tuberkulosis}

\author{
Santalia Banne Tondok ${ }^{1 *}$, Emirensiana Watu², Wahyuni ${ }^{3}$ \\ 1Prodi Pendidikan Ners Jurusan Keperawatan Politeknik Kesehatan Kemenkes Jayapura. \\ Korespondensi Penulis: Santalia Banne Tondok. *Email: sta.vicky@gmail.com \\ ${ }^{2}$ Akademi Keperawatan St. Elisabeth Lela Maumere. \\ ${ }^{3}$ Puskesmas Kemtuk Kabupaten Jayapura.
}

\begin{abstract}
Validity instrument European Quality of Life (EQ-5D-5L) Indonesian version to assess the quality of life patients with tuberculosis
\end{abstract}

Background: Tuberculosis is an infectious disease that can cause death and easily contract droplets through the air. TB sufferers will experience some clinical symptoms that indirectly improve their quality of life. Measuring the cauldron of living bags in patients with tuberculosis is still rare in Indonesia, especially by using the Instrument European Quality of Life EQ-5D-5L Indonesian version.

Purpose: To determine the validity and reliability of the EQ-5D-5L instrument with the Indonesian version of the utility set index as an alternative to measuring the quality of life of TB patients in Indonesia.

Method: A cross-sectional study with an observational approach, conducted on patients with tuberculosis at Sentani Jayapura public health centre cover area I, using the Indonesian version of the EQ-5D-5L instrument.

Results: Based on Pearson Correlation tests on 5 EQ-5D-5L domains showed a significant value of 0.000 on each question item and was declared valid with a correlation value between $\geq 0.60-0.80$, while the reliability test obtained a Cronbach Alpha value of 0.799 . Overall the EQ-5D-5L instrument is accurate and reliable. Tool EQ$5 \mathrm{D}-5 \mathrm{~L}$ Indonesian version can be used to assess the quality of TB patients in Indonesia with a value of Pearson Correlation $r=>0.50$ and Cronbach Alpha $0.799(>0.70)$.

Conclusion: The EQ-5D-5L instrument with the Indonesian version of the utility set index can be used to assess the quality of life of TB patients in Indonesia.

\section{Keywords : Patient; Tuberculosis; Quality of Life; Instrument}

Pendahuluan: Tuberkulosis merupakan penyakit menular yang dapat menyebabkan kematian dan mudah tertulari oleh droplet melalui udara. Penderita TB akan mengalami beberapa gejala klinis yang secara tidak langsung mempengaruhi kualitas hidup mereka. Mengukur kualitas hidup pada penderita tuberkulosis masih jarang dilakukan di Indonesia terutama dengan menggunakan instrumen European Quality of Life EQ-5D-5L versi Indonesia.

Tujuan: Mengetahui validitas dan reliabilitas instrumen EQ-5D-5L dengan index utility set versi Indonesia sebagai alternatif mengukur kualitas hidup pasien TB di Indonesia. 
Validitas instrumen European Qualitiy of Life (EQ-5D-5L) Versi Indonesia untuk menilai kualitas hidup penderita tuberkulosis

Metode: Menggunakan rancangan cross sectional dengan pendekatan observasi. Tempat penelitian di Puskesmas Sentani Kabupaten Jayapura, dilakukan padan pasien TB kategori I, menggunakan instrumen EQ5D-5L versi Indonesia.

Hasil: Berdasarkan uji Pearson Correlation pada 5 domain EQ-5D-5L menunjukkan nilai yang signifikan yaitu 0.000 pada tiap item pertanyaan dan dinyatakan valid dengan nilai korelasi antara $\geq 0.60-0.80$, sedangkan uji reliabilitas diperoleh nilai Cronbach Alpha 0.799. Secara keseluruhan instrumen EQ-5D-5L adalah valid dan reliabel. Instrumen EQ-5D-5L versi Indonesia dapat di gunakan untuk menilai kualitas pasien TB di Indonesia dengan nilai Pearson Correlation $r=>0.60$ dan Cronbach Alpha $0.799(>0.70)$.

Simpulan: Instrumen EQ-5D-5L dengan index utility set versi Indonesia dapat digunakan untuk menilai kualitas hidup pasien TB di Indonesia.

\section{Kata Kunci : Pasien; Tuberkulosis; Kualitas Hidup; Uji validitas; Instrumen}

\section{PENDAHULUAN}

Tuberkulosis merupakan penyakit menular yang dapat menyebabkan kematian akibat infeksius bakteri TB dan penyumbang kematian terbesar kedua di dunia setelah HIV AIDS (World Health Organization, 2020). Penyakit TB disebabkan oleh mycobacterium tuberculosis $s p$ dan menular melalui air ludah dari pasien TB yang beterbangan di udara (Mohamad, Porotu'o, \& Homenta, 2016; Murwani, 2011). Seseorang yang terserang TB paru biasanya mengalami gejala klinis seperti batuk, demam, sesak dan penurunan berat badan (WHO, 2016).

World Health Organization (WHO) menjelaskan bahwa TB sebagai penyakit menular Kasus TB di Indonesia merupakan kasus yang belum terselesaikan meskipun program pengendalian TB telah dilakukan namun kasus TB belum menunjukkan penurunan angka yang signifikan dan masih menjadi perhatian pemerintah dan kesehatan (Kementerian Kesehatan Republik Indonesia, 2018).

Berdasarkan data WHO (2020) secara Global diperkirakan 10 juta dengan kisaran 8.9-11 juta orang menderita penyakit TBC dan diperkirakan 1.2 juta dengan kisaran 1.1 - 1.3 juta orang meninggal dunia karena penyakit ini. Negara India, China, Philipina, Pakistan dan salah satunya adalah negara Indonesia lima negara dengan kasus TB terbesar di dunia. Kasus TB di Indonesia pada tahun 2017 sebesar 420.994 kasus dan jumlah kasus TB di Papua tahun 2017 adalah 7.354 kasus dan data TB di Puskesmas Sentani sebesar 156 kasus TB kategori I. (Kementerian Kesehatan Republik Indonesia, 2018).

Tuberkulosis dapat disembuhkan dengan pengobatan dan perawatan yang sesuai. Tahapan pengobatan TB terdiri dari dua yaitu tahap intensif dan lanjutan dan pengobatan yang teratur dan sesuai dapat mempengaruhi kualitas hidup pasien. Semakin baik pengobatan semakin baik pula status kesehatan pasien. Kualitas hidup merupakan respon individu terhadap aspek kehidupannya yaitu fisik, mental, aktivitas dan sosial budaya. Kuesioner EQ-5D-5L merupakan kuesioner generic yang menggunaan value set utility untuk mengetahui status kesehatan pasien. Kuesioner ini dikembangkan di Eropa dan telah banyak digunakan di berbagai negara di dunia termasuk Indonesia. EQ-5D-5L terdiri dari 5 domain dan 5 tingkatan kondisi pasien (Oemar, \& Janssen, 2013; World Health Organization, 2016).

\section{METODE}

Penelitian ini menggunakan rancangan cross sectional dengan pendekatan observasional. Data dikumpulkan sekali di Puskesmas Sentani Kabupaten Jayapura pada bulan April 2021. Sampel penelitian ini adalah penderita TB kategori 1 usia $\geq 16$ tahun, kooperatif dan tidak memiliki penyakit penyerta yang datang berobat berjumlah 76 orang. Teknik pengambilan sampel dilakukan secara simple random sampling. Penelitian ini telah memiliki izin etik NO. 05/KEPK-J/IV/2021.

Pengumpulan data menggunakan instrumen European Quality of Life EQ-5D-5L versi Indonesia dengan value set utility versi Indonesia untuk

\section{Santalia Banne Tondok ${ }^{1 *}$, Emirensiana Watu ${ }^{2}$, Wahyuni ${ }^{3}$}

\footnotetext{
'Prodi Pendidikan Ners Jurusan Keperawatan Politeknik Kesehatan Kemenkes Jayapura.

Korespondensi Penulis: Santalia Banne Tondok. *Email: sta.vicky@gmail.com

${ }^{2}$ Akademi Keperawatan St. Elisabeth Lela Maumere.

${ }^{3}$ Puskesmas Kemtuk Kabupaten Jayapura.
} 
Validitas instrumen European Qualitiy of Life (EQ-5D-5L) Versi Indonesia untuk menilai kualitas hidup penderita tuberkulosis

menilai validitas dan reliabilitas. Instrumen ini telah banyak di translasi dalam berbagai bahasa termasuk di Indonesia dan diuji validitas dan reliabilitasnya (Oemar, \& Janssen, 2013).

Pada penelitian sebelumnya instrumen ini telah digunakan pada beberapa kasus penyakit seperti Osteoarthritis, Diabetes Melitus dan memiliki nilai index utility versi Indonesia (Purba et al, 2017; Pramono \& Isbagio, 2010; Arifin, Purba, Herman, Adam, \& Atthobari, 2020).

Instrumen ini terdiri dari 5 domain yaitu kemampuan berjalan, kemampuan perawatan diri, kegiatan yang biasa dilakukan, nyeri dan cemas. Setiap domain terdiri dari 5 level yaitu level 1: tidak kesulitan; level 2: sedikit kesulitan; level 3: cukup kesulitan; level 4: sangat kesulitan; level 5: ekstrim dan responden diminta untuk memilih salah satu antara 1: 'tidak ada masalah' hingga 5: 'tidak dapat/masalah ekstrem'. Nilai Indeks utility EQ-5D5L dari '11111 sampai dengan 55555'. Value set utility Indonesia untuk '11111' adalah 1,000 dinilai sebagai status kesehatan terbaik, '55555' adalah 0,865 dinyatakan sebagai status kesehatan penderita lebih buruk dari meninggal / sakit yang sangat menderita dan nilai indeks utility 0 untuk status kesehatan terburuk (meninggal) (Oemar, \& Janssen, 2013; Purba et al, 2017). Analisis data dilakukan dengan menggunakan SPSS-23. Uji validitas instrumen EQ-5D-5L menggunakan Pearson Correlation dan uji reliabilitasnya menggunakan Cronbach Alpha. Apabila nilai $r$ hitung $>r$ tabel makan instrumen tersebut dinyatakan valid dan reliabel bila nilai $r>0.60$.

\section{HASIL}

Tabel 1.Distribusi Karakteristik Responden N=76

\begin{tabular}{lc}
\hline Variabel & Hasil \\
\hline Data Demografi & $29.44 \pm 12.04$ \\
Usia (Mean \pm SD) (Rentang)(Tahun) & $(16-65)$ \\
& \\
Jenis Kelamin (n/\%) & $46 / 60.53$ \\
$\quad$ Laki-laki & $30 / 39.47$ \\
$\quad$ Perempuan & \\
Status Merokok (n/\%) & \\
$\quad$ Merokok & $27 / 35.52$ \\
$\quad$ Tidak Merokok & $49 / 64.48$ \\
& \\
Etnik (n/\%) & \\
$\quad$ Papua & $53 / 69.74$ \\
$\quad$ Non Papua & $23 / 30.26$ \\
$\quad$ & \\
Pendidikan (n/\%) & \\
$\quad$ Rendah & $17 / 22.37$ \\
$\quad$ Menengah & $43 / 56.58$ \\
$\quad$ Tinggi & $16 / 31.05$ \\
Lama Pengobatan (n/\%) & \\
$\quad$ Intensif & \\
Lanjutan & $33 / 43.42$ \\
\hline
\end{tabular}

Santalia Banne Tondok ${ }^{1 *}$, Emirensiana Watu ${ }^{2}$, Wahyuni ${ }^{3}$

'Prodi Pendidikan Ners Jurusan Keperawatan Politeknik Kesehatan Kemenkes Jayapura.

Korespondensi Penulis: Santalia Banne Tondok. *Email: sta.vicky@gmail.com

${ }^{2}$ Akademi Keperawatan St. Elisabeth Lela Maumere.

${ }^{3}$ Puskesmas Kemtuk Kabupaten Jayapura. 
Validitas instrumen European Qualitiy of Life (EQ-5D-5L) Versi Indonesia untuk menilai kualitas hidup penderita tuberkulosis

Berdasarkan karakteristik responden menunjukkan usia rata-rata 29.44 tahun dengan standar deviasi 12.04 dan rentang 16 sampai 65 tahun, jenis kelamin laki-laki 60,53\% tidak merokok, $64.48 \%$ etnik papua $69,74 \%$, berpendidikan menengah, 56,58 \% serta menjalani pengobatan fase lanjutan. 56,58

Tabel 2. Kuesioner EQ-5D-5L Versi Indonesia

\begin{tabular}{lc}
\hline Kemampuan Berjalan & $\square$ \\
\hline Tidak kesulitan dalam berjalan & $\square$ \\
Sedikit kesulitan dalam berjalan & $\square$ \\
Cukup kesulitan dalam berjalan & $\square$ \\
Sangat kesulitan dalam berjalan & $\square$ \\
Tidak bisa berjalan & \\
\hline
\end{tabular}

\section{Perawatan Diri}

Tidak kesulitan untuk melakukan perawatan diri

Sedikit kesulitan untuk melakukan perawatan diri

Cukup kesulitan untuk melakukan perawatan diri

Sangat kesulitan untuk melakukan perawatan diri

Tidak bisa untuk melakukan melakukan perawatan diri

\section{Kegiatan yang Biasa Dilakukan \\ Tidak kesulitan dalam melakukan kegiatan \\ Sedikit kesulitan dalam melakukan kegiatan \\ Cukup kesulitan dalam melakukan kegiatan \\ Sangat kesulitan dalam melakukan kegiatan \\ Tidak bisa melakukan kegiatan}

\begin{tabular}{lc}
\hline Rasa Nyeri /Tidak Nyaman & $\square$ \\
\hline Tidak merasa nyeri /tidak nyaman & $\square$ \\
Sedikit merasa nyeri /tidak nyaman & $\square$ \\
Cukup merasa nyeri /tidak nyaman & $\square$ \\
Merasa sangat nyeri / tidak nyaman & $\square$ \\
Merasa amat sangat nyeri / tidak nyaman & $\square$ \\
\hline Rasa Cemas / Depresi (Sedih) & $\square$ \\
\hline Tidak merasa cemas/depresi & $\square$ \\
Sedikit merasa cemas/depresi & $\square$ \\
Cukup merasa cemas/depresi & $\square$ \\
Merasa sangat cemas/depresi & $\square$ \\
\hline
\end{tabular}

Santalia Banne Tondok ${ }^{1 *}$, Emirensiana Watu' ${ }^{2}$ Wahyuni ${ }^{3}$

'Prodi Pendidikan Ners Jurusan Keperawatan Politeknik Kesehatan Kemenkes Jayapura.

Korespondensi Penulis: Santalia Banne Tondok. *Email: sta.vicky@gmail.com

${ }^{2}$ Akademi Keperawatan St. Elisabeth Lela Maumere.

${ }^{3}$ Puskesmas Kemtuk Kabupaten Jayapura. 
Validitas instrumen European Qualitiy of Life (EQ-5D-5L) Versi Indonesia untuk menilai kualitas hidup penderita tuberkulosis

Tabel 3. Hasil Uji Validitas dan Reliabilitas Kuesioner EQ-5D-5L Versi Indonesia

\begin{tabular}{lccc}
\hline \multicolumn{1}{c}{ Domain } & Signifikansi & $\begin{array}{c}\text { Validitas } \\
\text { Correlation Pearson }\end{array}$ & $\begin{array}{c}\text { Reliabilitas } \\
\text { Cronbach Alpha }\end{array}$ \\
\hline - Kemampuan Berjalan & 0.000 & 0.752 & 0.799 \\
- Kemampuan Perawatan Diri & 0.000 & 0.680 & \\
- Kemampuan Kegiatan yang & 0.000 & 0.805 & \\
$\begin{array}{l}\text { Biasa Dilakukan } \\
\text { - Nyeri }\end{array}$ & 0.000 & 0.686 & \\
- Kecemasan/ Depresi & 0.000 & 0.791 & \\
\hline
\end{tabular}

Berdasarkan uji Pearson Correlation pada kelima domain EQ-5D-5L menunjukkan nilai yang signifikan yaitu 0.000 pada tiap item pertanyaan dan dinyatakan valid dengan nilai korelasi antara $\geq$ $0.60-0.80$, sedangkan uji reliabilitas diperoleh nilai Cronbach Alpha 0.799. Secara keseluruhan instrumen EQ-5D-5L adalah valid dan reliabel.

\section{PEMBAHASAN}

Uji validitas merupakan keandalan pengukuran suatu instrumen terhadap item pertanyaan. Suatu instrumen dinyatakan valid apabila nilai $r$ hitung yang diperoleh > dari $r$ tabel (Adamson \& Prion, 2013; Sugiyono, 2017). Pengukuran validitas dan reliabilitas sangat diperlukan dalam mengukur suatu keabsahan sebuah alat ukur seperti instrumen. Misalkan instrumen yang digunakan untuk menilai kualitas hidup penderita penyakit kronik adalah WHOQOL-BREF, SF-36 dan EuroQoL- 5 Dimension (EQ-5D) yang memiliki kelebihan dan kelemahan masing - masing.

Pentingnya kuesioner sebagai alat pengumpulan data untuk digunakan dalam penelitian sehingga menghasilkan alat ukur yang sesuai dengan tujuan penelitian. Item-item kuesioner harus sesuai dengan hipotesis penelitian. Validitas dan reliabilitas instrumen perlu diketahui sebelum digunakan dalam dalam suatu penelitian dengan kriteria responden yang memiliki ciri atau karakteristik dari tempat di mana penelitian tersebut harus dilaksanakan (Widi, 2011). Pada pengujian validitas instrumen koefisien korelasi yang tinggi antara item pertanyaan dengan item keseluruhan menunjukkan tingginya konsistensi antara nilai keseluruhan tes dengan semua nilai item pertanyaan sedangkan reliabilitas menyatakan hasil pengukuran dapat diterima apabila dilakukan secara berulang kali pada responden yang sama, didapatkan hasil pengukuran yang memiliki kesamaan, dan komponen pada responden yang diukur harus diubah (Matondang, 2009).

Hasil penelitian ini menyatakan bahwa instrumen EQ-5D-5L versi Indonesia dinyatakan valid dengan nilai indeks validitas $0.60-0.80$ Semakin besar nilai (mendekati nilai 1) yang diperoleh semakin kuat korelasi instrumen tersebut (Yusup, 2018). Nilai $r$ pada tiap domain EQ-5D yang diukur pada pasien TB semuanya bermuatan positif dengan nilai siginifikansi adalah 0.000 yang berarti instrumen tersebut bisa diterapkan untuk mengukur kualitas hidup penderita TB di Indonesia. Hasil yang diperoleh sama dengan penelitian yang dilakukan Yugo et al, (2018) di RSUD Ulin Bajarmasin pada pasien Gagal Ginjal Kronik. Sari et al, (2015) juga menjelaskan hasil yang sama bahwa nilai yang diperoleh valid dan reliabel pada pasien Hipertensi di Yogyakarta. Begitu juga Claire M, Nolan et al, (2016) memperoleh hasil yang sama yaitu $r=0.47-0.72$ pada pasien COPD di Inggris.

Hasil uji reliabilitas pada instrumen EQ-5D-5L versi Indonesia dengan menggunakan Cronbach Alpha adalah $>0.70$ yang berarti instrumen tersebut reliabel. Indeks tersebut menjelaskan semakin tinggi nilai Cronbach Alpha atau mendekati nilai 1 semakin reliabel instrumen tersebut (Adamson \& Prion, 2013), di mana nilai 0.799 termasuk kategori tinggi. Hal ini menjelaskan bahwa penilaian kualitas hidup pasien

\footnotetext{
Santalia Banne Tondok ${ }^{1 *}$, Emirensiana Watu ${ }^{2}$, Wahyuni ${ }^{3}$

'Prodi Pendidikan Ners Jurusan Keperawatan Politeknik Kesehatan Kemenkes Jayapura.

Korespondensi Penulis: Santalia Banne Tondok. *Email: sta.vicky@gmail.com

${ }^{2}$ Akademi Keperawatan St. Elisabeth Lela Maumere.

${ }^{3}$ Puskesmas Kemtuk Kabupaten Jayapura.
} 
Validitas instrumen European Qualitiy of Life (EQ-5D-5L) Versi Indonesia untuk menilai kualitas hidup penderita tuberkulosis

TB di Indonesia dapat menggunakan instrumen EQ-5D-5L. Penilaian kualitas hidup dengan instrumen ini dapat dijadikan sebagai bahan evaluasi selanjutnya dalam pengobatan terhadap pasien.

\section{SIMPULAN}

Instrumen EQ-5D-5L dengan value set utility versi Indonesia dapat di gunakan untuk menilai kualitas pasien TB di Indonesia.

\section{DAFTAR PUSTAKA}

Adamson, K. A., \& Prion, S. (2013). Reliability: measuring internal consistency using cronbach's a. Clinical Simulation in Nursing, 9, 179-180.

Alfian, R., Rahim, Z., \& Karani. (2018). Uji validitas dan reliabilitas kuesioner eq-5d bahasa indonesia untuk mengukur kualitas hidup pasien hemodialisa gagal ginjal kronik. Jurnal Ilmiah Manuntung, 4(1), 41-47.

Arifin, B., Purba, F. D., Herman, H., Adam, J. M. F., \& Atthobari, J. (2020). Comparing the EQ-5D-3 $L$ and EQ-5D-5 $L$ : Studying measurement and scores in Indonesian type 2 diabetes mellitus patients, 1-10.

Claire M Nolan, Louise, L., Joanne, Lord, Canavan, J. L., Jones, S. E., Kon, S. S. C., \& Man, W. D.C. (2016). The EQ-5D-5L health status questionnaire in COPD:validity, responsiveness and minimum importantdifference. Chronic Obstructive Pulmonary Disease, 71, 493-500. https://doi.org/doi:10.1136/thoraxjnl-201520778

Kementerian Kesehatan Republik Indonesia. (2004). Sistem Kesehatan Nasional. Diakses dari:

https://peraturan.bkpm.go.id/jdih/userfiles/batan g/KEPMENKES_131_2004.pdf
Kementerian Kesehatan Republik Indonesia. (2018). Riskesdas: angka kejadian 10 penyakit di Indonesia. Retrieved from https://www.litbang.kemkes.go.id/laporan-risetkesehatan-dasar-riskesdas Kementerian

Matondang, Z. (2009). Validitas dan reliabilitas suatu instrumen penelitian. Jurnal Tabularasa PPS UNIMED, 6(1), 87-97.

Mohamad, R., Porotu'o, J., \& Homenta, H. (2016). Hasil diagnostik Mycobacterium tuberculosis pada penderita batuk $\geq 2$ minggu dengan pewarnaan Ziehl-Neelsen di Puskesmas Ranomuut dan Puskesmas Kombos Manado. Jurnal E-Biomedik, 4(2). Retrieved from https://www.neliti.com/publications/68636/hasildiagnostik-mycobacterium-tuberculosis-padapenderita-batuk-2-minggu-dengan

Murwani, A. (2011). Perawatan pasien penyakit dalam. Yogyakarta: Gosyen Publishing.

Oemar, M \& Janssen, B. (2013). EQ-5D-5L User guide. Basic information on how to use the EQ5D-5L instrument. EuroQol Group. Retrieved from

http://www.eurogol.org/fileadmin/user upload/D ocumenten/\%0APDF/Folders Flyers/UserGuid e_EQ-5D-5L_v2.0_October_2013. Diakses 10 Februari 2019

Pramono, A., \& Isbagio, H. (2010). Reliability and validity of European Quality of Life 5 Dimension ( EQ-5D ) for measuring health-related quality of life in knee osteoarthritis patients at Cipto Mangunkusumo General Hospital, 02, 19-25.

Purba, F. D., Hunfeld, J. A. M., Iskandarsyah, A., Passchier, J., \& Busschbach, J. J. V. (2017). The Indonesian EQ-5D-5L Value Set, 11531165. https://doi.org/10.1007/s40273-017-05389

Santalia Banne Tondok ${ }^{1 *}$, Emirensiana Watu' ${ }^{2}$ Wahyuni ${ }^{3}$

'Prodi Pendidikan Ners Jurusan Keperawatan Politeknik Kesehatan Kemenkes Jayapura.

Korespondensi Penulis: Santalia Banne Tondok. *Email: sta.vicky@gmail.com

${ }^{2}$ Akademi Keperawatan St. Elisabeth Lela Maumere.

${ }^{3}$ Puskesmas Kemtuk Kabupaten Jayapura. 
Validitas instrumen European Qualitiy of Life (EQ-5D-5L) Versi Indonesia untuk menilai kualitas hidup penderita tuberkulosis

Sari, A., Lestari, N. Y., \& Perwitasari, D. A. (2015). Validasi St European Quality of Life-5 Dimensions ( EQ-5D ) Versi Indonesia Pada Pasien Hipertensi di Puskesmas Kotagede II Yogyakarta. Pharmaçiana, 5(2), 131-138. Retrieved from http://journal.uad.ac.id/index.php/PHARMACIA NA/article/view/248

Sugiyono, S. (2017). Metode Penelitian Kuantitatif, Kualitatif dan R\&D (25th ed.). Bandung: CV Alfabeta.

Widi, R. (2011). Uji validitas dan reliabilitas dalam penelitian epidemiologi kedokteran gigi. Stomatognatic (JKG Unej), 8(1), 27-34.

World Health Organization. (2016). End TB Strategy: Global Strategy and Targets for Tuberculosis Prenvention Care and Control. America : World Health Organization.
World Health Organization. (2016b). Global Tuberculosis Report 2016. Switzerland: World Health Organization.

World Health Organization. (2020). Global Tuberculosis Report. Retrieved from http://apps.who.int/iris.

Yugo, S., Alfian, R., Rahim, Z., \& Karani. (2018). Uji validitas dan reliabilitas kuesioner eq-5d bahasa indonesia untuk mengukur kualitas hidup pasien hemodialisa gagal ginjal kronik. Jurnal IImiah Manuntung, 4(1), 41-47.

Yusup, F. (2018). Uji Validitas dan Reliabilitas Instrumen Penelitian Kuantitatif. Jurnal Tarbiyah: Jurnal IImiah Kependidikan, 7(1), 1723.

Santalia Banne Tondok ${ }^{1 *}$, Emirensiana Watu ${ }^{2}$, Wahyuni ${ }^{3}$

'Prodi Pendidikan Ners Jurusan Keperawatan Politeknik Kesehatan Kemenkes Jayapura.

Korespondensi Penulis: Santalia Banne Tondok. *Email: sta.vicky@gmail.com

${ }^{2}$ Akademi Keperawatan St. Elisabeth Lela Maumere.

${ }^{3}$ Puskesmas Kemtuk Kabupaten Jayapura. 